\title{
CLINICAL PROFILES OF CHRONIC KIDNEY DISEASE PATIENTS AT THE TIME OF MAIDEN PRESENTATION: AN EXPERIENCE AT THE NEPHROLOGY WARD, CHITTAGONG MEDICAL COLLEGE HOSPITAL
}

\author{
Abul Kashem ${ }^{1}$ Pradip Kumar Dutta ${ }^{1}$ Md Nurul Huda ${ }^{2}$ \\ Saibal Das ${ }^{2}$ Emran Bin Yunus ${ }^{3}$ Dipti Chowdhury ${ }^{3}$
}

\begin{abstract}
Summary
The quality of care of patients with Chronic Kidney Disease (CKD) in their predialysis/transplantation state is known to have a significant impact on the mortality and morbidity of renal failure patients. We studied the clinical profiles of patients who had been admitted with maiden diagnosis of CKD to the nephrology ward, Chittagong Medical College Hospital (CMCH). A total of 115 CKD patients was evaluated who had been admitted during the period of January' 05 to December' 06. Etiological factors and different laboratory parameters were studied at the time of admission. The mean age of the patients was below 42 years. Chronic Glomerulonephritis was the leading cause of CKD, found in $48(41.8 \%)$ of patients, followed by Diabetes Mellitus 30 (26.1\%), Hypertension 15 (13\%), Obstructive Uropathy 15 (13\%) and Others $7(6.1 \%)$. At the time of admission, the mean blood urea was $156.7 \pm 63.5$ $\mathrm{mg} / \mathrm{dl}$, serum creatinine was $10.1 \pm 6.5 \mathrm{mg} / \mathrm{dl}$, and hemoglobin was $8.4 \pm 3.3 \mathrm{gm} / \mathrm{dl}$. The mean value of creatinine clearance (calculated) was $10.0 \pm 6.8$ $\mathrm{m} / \mathrm{min}$. Seventy percent of the patients were in a state of severe renal failure at their first diagnosis. Our findings suggest that primary care physicians should be more aware of about the renal status in different co-morbid conditions and timing in referral of CKD patients for the nephrological services so that there will be enough time for predialysis/transplantation care which can improve the quality of life with better outcome of these patients.
\end{abstract}

\section{Key words}

CKD patients; Renal status at maiden presentation; Nephrology ward of $\mathrm{CMCH}$

Introduction

The incidence and prevalence of Chronic Kidney Disease (CKD) have been steadily up-surging worldwide ${ }^{l}$, including Bangladesh ${ }^{2}$. This increasing volume of CKD patients requires more and more dialysis and transplantation which is causing a heavy economical burden to the health care providers 1 .

1. Associate Professot of Nephrology

Chittagong Medical College, Chittagong.

2. Assistant Professor of Nephrology

Chittagoag Medical College, Chittagong.

3. Professor of Nephrology

Chitaagong Medical College, Chittagong.

Correspondence : Dr Abul Kashem
In Bangladesh, there are about 20 million people suffer from CKD and about 20 thousand CKD patients are becoming end stage renal diseasc (ESRD) per year ${ }^{2}$.

This equates with huge budget allocation for funding dialysis/transplantation procedure for this bulk ESRD patients. So, attention is now being paid to care of patients at pre-ESRD state, since it has been shown to play an important role to slow down the progression of disease process in some cases, and to modify the mortality/morbidity and quality of life of patients when started dialysis ${ }^{3}$. In spite of considerable efforts dedicated to the care of ESRD patients, and remarkable improvement in the quality of dialysis such as increased dose of dialysis, use of biocompatible dialyzer, and use of erythropoietin, the annual mortality rate among dialysis patients still remains high such as $22 \%$ in America $^{4}$, and $14.4 \%$ in Europe ${ }^{5}$. This has lead to search for other modifiable factors those could improve the outcome of ESRD patients on dialysis. Among these, early diagnosis and timely referral of CKD patients to the nephrological services and providing quality of nephrological care before initiation of dialysis have been shown to reduce the mortality/morbidity of ESRD patients significantly ${ }^{3}$. Early detection and proper care of CKD patients might retard its progression, prevent uremic complications, give more attention to co-morbid conditions, and provide adequate preparation for dialysis/transplantation. We designed this study to evaluate the renal status of patients who had admitted to our nephrology ward with first time diagnosis of CKD.

Patients and methods

A total of one hundred and fifteen CKD patients were included in this study who were first time admitted with 1st time CKD diagnosis to our nephrology ward either through the out patient department (OPD)/emergency department or as a referral case from other disciplines during the tenure of January'04 to December'05. Patients who were admitted with previous diagnosis of CKD and who declined to give consent for study were excluded from the study. At the time of admission, a preformed standardized unified form was used to record the disease history, age, sex, body weight, laboratory data, and radiological assessment of kidneys and renal histology (when available). An informed consent from the patients and an Ethical clearance from the Institutional Ethical Committee were taken. 
Etiology of CKD was determined upon the detailed case history, a comprehensive clinical examination and laboratory data including available radiological and biopsy reports. The patients in whom case history, clinical examination, laboratory data did not reveal any specific cause of chronic kidney disease, were labeled as CGN group. The laboratory data such as proteinuria, blood urea, serum creatinine, hemoglobin level were recorded. The creatinine clearance rate $(\mathrm{Ccr})$ was calculated by the Cockroft and Gault formula: $\mathrm{Ccr}=(140-$ age $) \mathrm{x}$ body weight $(\mathrm{kg}) \div$ serum creatinine $(\mathrm{mg} / \mathrm{dl}) \times 72$. The calculated clearance was reduced by $15 \%$ for female patients. All CKD patients were stratified into 5 stages (stage I to stage V) based on calculated $\mathrm{Ccr}$. values. $\mathrm{CKD}$ stage $\mathrm{I}=\mathrm{Ccr}$ is $>90 \mathrm{ml} / \mathrm{min}$; $\mathrm{CKD}$ stage $\mathrm{II}=\mathrm{Ccr}$ is $60-90 \mathrm{ml} / \mathrm{min}$; CKD stage III $=\mathrm{Ccr}$ is $30-59 \mathrm{ml} / \mathrm{min}$; CKD stage IV $=\mathrm{Ccr}$ is $15-29$ $\mathrm{ml} / \mathrm{min}$; and $\mathrm{CKD}$ stage $\mathrm{V}=\mathrm{Ccr}$ is $<15 \mathrm{ml} / \mathrm{min}$ (in diabetic nephropathy cases) and $<10 \mathrm{ml} / \mathrm{min}$ (in non-diabetic cases).

Statistical analysis

All data are shown as mean $\pm \mathrm{SD}$

\section{Results}

A total of one hundred and fifteen CKD patients with first time diagnosis were admitted to our nephrology ward by 24 months. There were 78 males $(67.8 \%)$ and 37 females $(32.2 \%)$. The mean age was $48.5 \pm 18.4$ years, ranged from 16 to 75 years. The majority patients $(38.8 \%)$ were below 40 yrs of age and the age break down of patients was shown in table I.

Table I : Age distribution of patients

\begin{tabular}{lll}
\hline St \# & Age range (years) & Number of patients \\
\hline 1 & $16-30$ & $30(26.0 \%)$ \\
2 & $31-40$ & $25(21.3 \%)$ \\
3 & $41-50$ & $30(26.0 \%)$ \\
4 & $51-60$ & $20(17.4 \%)$ \\
5 & $61-70$ & $05(04.4 \%)$ \\
6 & $>70$ & $05(04.4 \%)$ \\
\hline
\end{tabular}

Table II : Etiology of Chronic Kidney Disease

\begin{tabular}{lll}
\hline Serial I Etiology & $\begin{array}{l}\text { No of patients } \\
\text { with percenuge }\end{array}$ \\
\hline 1 & Chronic & \\
& Glomerulonephritis (CGN) & $48(41.8 \%)$ \\
2 & Diabctic Nephropathy (DN) & $30(26.1 \%)$ \\
3 & Hypertension (HTN) & $15(13.0 \%)$ \\
4 & Obstructive Uropathy (OUP) & $15(13.0 \%)$ \\
5 & Others & $07(06.1 \%)$
\end{tabular}

The etiology of CKD is shown in table II.
Chronic glomerulonephritis (CGN) was the commonest cause of CKD diagnosed in $48(41.8 \%)$ followed by Diabetes Mellitus (DM) in $30(26.1 \%)$, Hypertension in $15(13 \%)$, Obstructive Uropathy in $15(13 \%)$, others in $7(6.1 \%)$. Six cases $(5.2 \%)$ were biopsy proven glomerulonephritis.

The laboratory parameters at the time of admission with first diagnosis of CKD are shown in table III.

Table III : Laboratory parameters of patients at their maiden admission to nephrology ward

\begin{tabular}{lll}
\hline Laboratory parameters & Mean values & Range values \\
\hline Hemoglobin (gm/d) & $8.4 \pm 3.3$ & $4-14$ \\
Blood urea (mg/d) & $156.7 \pm 63.5$ & $55-234$ \\
Serum creatinine (mg/d) & $10.1 \pm 6.5$ & $2.2-18.5$ \\
Creatinine clearance (ml/min) & $10.0 \pm 6.8$ & $3-32$ \\
\hline
\end{tabular}

The mean value of blood urea was $156.7 \pm 63.5$ $\mathrm{mg} / \mathrm{dl}$, serum creatinine was $10.1 \pm 6.5 \mathrm{mg} / \mathrm{dl}$. creatinine clearance $(\mathrm{Ccr})$ was $10.0 \pm 6.8 \mathrm{ml} / \mathrm{min}$. Out of 115 CKD patients, 90 (78.3\%) patients were in CKD stage-V, $20(17.4 \%)$ patients were in CKD stage-IV, and remaining $5(4.4 \%)$ patients were in CKD stage-III, as shown in table IV.

Table IV : Grading of CKD at the maiden presentation

\begin{tabular}{lll}
\hline Grading of CKD & $\begin{array}{l}\text { Range of creatinine } \\
\text { clearance }\end{array}$ & No of patients \\
\hline CKD stage- III & $30-59(\mathrm{ml} / \mathrm{min})$ & $05(4.4 \%)$ \\
CKD stage-IV & $15-29(\mathrm{ml} / \mathrm{min})$ & $25(21.7 \%)$ \\
CKD stage-V & $<15 \mathrm{ml} / \mathrm{min}$ in DN \& & $85(73.9 \%)$ \\
& $<10 \mathrm{ml} / \mathrm{min}$ in others &
\end{tabular}

The mean hemoglobin level was $8.4 \pm 3.3 \mathrm{gm} / \mathrm{dl}$ and in $35(30.4 \%)$ patients hemoglobin was below 6 $\mathrm{gm} / \mathrm{dl}$. No patient was receiving any erythropoietin therapy.

\section{Discussion}

Chronic glomerulonephritis (CGN) was found the most common cause $(41.8 \%)$ of CKD in our study which is consistent with the previous publication ${ }^{6}$. Still the prevalence of CGN as a cause of CKD is quite high in our country which might be due to low socioeconomic status, illiteracy, and lack of health consciousness prevailing in the society. Diabetes Mellitus was found as the second most cause (26.1\%) of CKD, although recently it emerges as the most common causes of CKD in the developing countries such as in USA', Europe ${ }^{7}$, Japan $^{8}$. Hypertension was also highly prevalent in our patients which are similar as reported earlier ${ }^{9}$. 
In fact, the diagnosis of Hypertension is not conclusive as hypertension is not only a cause but also a consequence of CKD. Although the etiology of CKD in our study are consistent with the previous published data, it does not confirm the real etiological picture as vast majority patients $(78.3 \%)$ were in a state of end stage renal disease at their first diagnosis when diagnosis of primary disease is mostly obscured. Moreover, the exact cause of CKD is difficult to determine in developing countries like us since medical facilities and diagnostic tools are still limited and unevenly distributed between urban and nural areas. Hence etiology of CKD still remains largely speculative in many cases at our situation.

There is growing awareness of a need not only to identify patients with CKD at an earlier stage of disease process but also to initiate treatment strategies earlier in order to delay the progression of CKD and co-morbid diseases ${ }^{10}$. Seventy eight percent of our CKD patients at their first diagnosis were in severe renal failure and $17 \%$ patients were in moderate renal failure which is relatively quite higher and alarming than the international trend ${ }^{11}$. This is likely due to either our low socioeconomic status or lack of health awareness among patients or reluctance of the primary physician to refer the patients to the nephrology centers with lower creatinine level, as observed in other studies ${ }^{12}$. However, a number of other explanations have to consider for this late presentation of CKD patients such as delayed diagnosis of CKD as the disease process is insidious in majority cases, there is no annual health check-up program either at national or individual level, and CKD patients seeks consultation only with late uremic symptoms. Moreover, we could not let admit all referred CKD patients except severe renal failure in our nephrology ward because of accommodation problem. On the other hand, the large majority patients are often treated by the general practitioners or internists without any distinct guidelines and facilities.

The challenge, currently facing by the nephrologists is how to improve the tools for early diagnosis of CKD and timelines of referral of these patients to nephrologists to minimize the consequences of late presentation. Although the renal function in severe renal failure patients who presented suddenly, might improve with acute dialysis but the co-morbid conditions, associated with CKD for a long time do not improve much, rather in many cases undermine the outcome of renal replacement therapy. Late presentation also limits therapeutic options and is associated with increased morbidity/mortality, increased need for frequent hospitalization and duration of hospital stay and thus, increased initial cost of caring following commencement of acute dialysis.
To resolve this issuc, at least partly, nephrologists should take initiatives in developing a guideline on CKD patient's management on the basis of local needs and facilities, patient's socioeconomic status especially focusing on how to diagnose, when to refer and hospitalize CKD patients. Since the management of progressive renal discase has become a challenge as well as an art, pre-dialysis stage of disease specifically needs efficient, professional and cost effective management. Previous studies showed that early pre-dialysis management of severe renal failure patients offers better survival even after dialysis ${ }^{13}$. Although disease progression is certain in chronic renal diseases and the need for renal replacement therapy is not a surprise, medical care providing in the relatively early phase of disease is expected to have the vision and insight to prepare the patients medically, financially, psychologically, and socially for facing the ensuing major changes in their lifestyle in dialysis/transplantation. In addition, early referral to the respective specialist working in a team with multidisciplinary expertise has been shown to delay the onset of renal replacement therapy due to stabilization or even improvement of renal function in many cases and thus reduce the cost of caring for the patients and the health care providers 13,14 . Although many different definitions have been used for "an early referral", it is suggested that patients with serum creatinine more than $2 \mathrm{mg} / \mathrm{dl}$ or $\mathrm{Ccr}<30 \mathrm{ml} / \mathrm{min}$ is high time for specialized management ${ }^{15}$. Canadian Society of Nephrology guidelines recommended that at least 12 months are needed prior to initiation of dialysis transplantation 15

\section{Conclusion}

Therefore active intervention is mandatory to promote early diagnosis and early referral of CKD patients to nephrology center to provide appropriate care to minimize complications and to prepare the affordable patients for future needful renal replacement therapy.

\section{Disclosure}

All the authors declared no competing interestes.

\section{References}

1. United State Renal Data System: USRDS 2000. Annual Data Report. Am J Kidney Dis 2000; 36 (Suppl 2):18-54

2. Rashid HU. Bangladesh Renal Registry Report. Bangladesh Renal J 2002; 2 I (1):25-28

3. Obrador GT, Pereira BJ. Early referral to the nephrologists and timely initiation of renal replacement therapy. Paradigm shift in the management of patients with chronic renal failure. Am J Kidney Dis 1998; 31:398-417 
4. Epidemiological Data of treated end stage renal failure patients in the European Union during the year 1995; Report of the European Renal Association Registry and the National Registries. Nephrol Dial Transplant 1999; 14:2332-2342

5. El-Rashid K, Jhony KV, Sugathan TN, Hakim A, Georgous M, Nampoory MR. End stage renal disease and renal replacement therapy in Kuwaitepidemiological profile over the past 4.5 years. Nephrol Dial Transplant 1994; 9-532-538

6. Rahman MH. End Stage Renal Faailure and it's management; present Bangladesh situation. Bangladesh Renal J 2002; 21:32-33

7. Rychlik I, Miltenberger-Mittenyi G, Ritz E. The drama of the continuous increase in the end stage renal failure patients with type II Diabetes Mellitus. Nephrol Dial Transplant 1998; 13:6-10

8. Sesso R, Belasco A. Late diagnosis of chronic renal failure and mortality on maintenance dialysis. Nephrol Dial Transplant 1996; 11:2417-2420

9. Dasgupta I, Madeley RJ, Pringle MA, Savill J, Burden RP. Management of hypertension in patients developing end stage renal failure. QMJ 1999; 92:519-525
10. Levin A. Consequence of late referral on patients outcomes. Nephrol Dial Transplant 1996; $11: 2417-2420$

11. Innes A, Rowe PA, Burden RP, Morgan AG. Early deaths on renal replacement therapy. The need for early nephrological referral. Nephrol Dial Transplant 1992; 7;467-471

12. Nissenson AR, Collins AJ, Hurley J, Peterson H, Pereira BJ, Steinburg EP. Opportunites for improving the caring of patients with chronic renal insufficiency; current practice patterns. J Am Soc Nephrol 2001; 12:1713-1720

13. McLaugh K, Manns B, Culleton B, Donaldson C, Taub K. An economic evaluation of early versus late referral of patients with progressive renal insufficiency. Am J Kidncy Dis 2001; 38:1122-1128

14. Eadington D. Delayed referral for dialysis. Higher mortality and higher costs. Semin Dial $1995 ; 8: 258-260$

15. Jungers P, Massy ZA, Nguyen Khoa $T$, et al. Longer duration of predialysis nephrological care is associated with improved long-term survival of dialysis patients. Nephrol Dial Transplant 2001: 16:2357-2364 